\title{
Peran Gender dalam Ritus Kusu Bue
}

\author{
Ida Ayu Putu Kartika Dewi *, Ni Made Wiasti, Aliffiati \\ Prodi Antropologi, Fakultas Ilmu Budaya, Unud \\ [tianonecke@gmail.com] \\ Denpasar, Bali, Indonesia \\ *Corresponding Author
}

\begin{abstract}
Kusu bue rite's a rite performed by women who have experience menstruation. Women will stay in a small house, called sao are. They cooperate with each other in every process of activity. The role of gender in the kusu bue rite also has implications for the Dona community. The formulation of the problem in this study are (1) how's the role of gender in the implementation of the kusu bue ? (2) What are the implications of gender roles in the implementation of the kusu bue of the kusu bue rite to the Dona community? This study uses theories from Marwell and theories about the transitional rites and the inauguration ceremony of Van Gennep. Ethnographic research models,including data collection techniques through observation, interviews, literature, studies, and data analysis field. The results explained that the kusu bue ritual process lasted for eight days and seven nights. The procession begins with preparation, hen enters theses'e ritual leadig to Soromazi, to Lole Sao Are. On the second day the community performed the Waju Pare Kobho. On the third and sixth day, why would they goon a journey to find the needs of the girls. Then on the seventh day the community carried out the Bora Raa Weti and Woke Tewu rituals. On the last day the kusu bue girls will have a graduation party or wela ripe. The result of this rite to the Dona community.These implications are the implication in the social, education, deliberation, and consensusand religious fields.
\end{abstract}

Keywords: Gender Role, Kusu Bue Rite, Implicationsof Gender Roles

\begin{abstract}
Abstrak
Ritus Kusu Bue merupakan ritus yang dilakukan oleh perempuan yag sudah mengalami menstruasi. Perempuan akan dipingit atau ruki di dalam rumah kecil yang bernama sao are. Pelaksanaan ritus kusu bue ini sangat dipengaruhi oleh peran laki-laki dan perempuan. Peran gender dalam ritus kusu bue ini juga memiliki implikasi terhadap masyarakat Dona. Rumusan masalah dalam penelitian ini yaitu (1) Bagaimana peran gender dalam pelaksanaan ritus kusu bue ? (2) Bagaimana Implikasi peran gender pada pelaksanaan ritus kusu bue terhadap masyarakat Dona ?. Penelitian ini bertujuan untuk mengetahui peran gender dalam setiap prosesnya serta mengetahui implikasi peran gender terhadap masyarakat Dona. Penelitian ini menggunakan teori fungsional dari Marwell dan teori mengenai ritus peralihan dan upacara pengukuhan oleh Van Gennep. Model penelitian etnografi dengan jenis penelitian kualitatif, meliputi teknik pengumpulan data melalui observasi, wawancara, studi pustaka, serta analisis data guna mengolah temuan lapangan. Hasil penelitian menjelaskan bahwa proses ritus kusu bue berlangsung selama delapan hari tujuh malam. Prosesi diawali dengan persiapan, kemudian masuk pada ritual ses'e menuju ke soromazi, hingga lole so
\end{abstract}


are. Pada hari kedua masyarakat melakukan ritual waju pare kobho. Hari ketiga dan keenam para ngapa melakukan perjalanan mecari kebutuhan para gadis. Kemudian pada hari ke tujuh masyarakat melaksanakan ritual bora raa weti dan woke tewu. Pada hari terakhir gadis kusu bue akan melakukan pesta tamat atau wela ripe. Hasil penelitian juga menemukan implikasi peran gender dalam pelaksanaan ritus kusu bue terhadap masyarakat Dona. Implikasi tersebut ialah implikasi dalam bidang sosial, pendidikan, musyawarah mufakat serta religi

Kata Kunci : Peran Gender, Ritus kusu bue, Implikasi Peran Gender.

\section{PENDAHULUAN}

Kabupaten Ngada merupakan salah satu Kabupaten yang terletak di Pulau Flores, Provinsi Nusa Tenggara Timur yang memiliki adat-istiadat yang masih kental, serta masih melestarikan warisan nenek moyang. Kabupaten Ngada mempunyai upacara inisiasi atau peralihan yaitu ritus Kusu Bue. Ritus Kusu Bue ini dilaksanakan di Kampung Dona Kecamatan Jerebu'u. Ritus Kusu Bue ini hanya dilaksanakan oleh masyarakat di Kecamatan Jerebu'u salah satunya kampung Dona

Ritus kusu bue merupakan bagian dari pelaksanaan upacara Reba. Upacara Reba adalah upacara yang dilaksanakan setiap akhir hingga awal tahun. Masyarakat Dona menyebutnya pesta akhir tahun dan awal tahun, dimana upacara ini sebagai bentuk rasa syukur dikarenakan telah menjalani tahun sebelumnya dengan baik serta berharap tahun selanjutnya agar lebih baik lagi. Upacara Reba dilaksanakan oleh seluruh masyarakat di Kabupaten Ngada, namun tidak untuk ritus kusu bue. Tidak semua masyarakat Ngada melakukan ritus kusu bue,salah satu masyarakat yang melakukan ritus kusu bue adalah masyarakat di Kampung Dona salah satunya pada masyarakat keturunan dari suku Tipo.

Ritus Kusu Bue merupakan upacara inisiasi atau proses pendewasaan untuk gadis yang sudah mengalami menstruasi atau akil balik. Pada saat pelaksanaan ritus kusu bue, para gadis akan dipingit di sebuah rumah kecil yang bernama sa'o are. Gadis yang melakukan kusu bue tersebut akan tinggal dan di pingit selama delapan hari tujuh malam. Para laki-laki tidak boleh melihat atau mengunjungi mereka ke tempat sa'o are.

Tujuan dari pingitan ini untuk mematangkan segala pola tingkah laku, mental anak gadis sehingga menajadi dewasa, menghimpun segala kekayaan hasil panen suku itu sebagai sarana pengendalian diri anak gadis dalam memasuki usia remaja agar tidak terjadi hal-hal yang menyimpang khususnya keperawanan para gadis demi mencapai kebahagiaan dan kesejahteraan hingga mencapai perkawinan (Asmarani, 2017: 3-4) Perempuan dipersepsikan oleh masyarakat sebagi aktor yang berperan sebagai figure ekspresif, yaitu sebagai pemelihara dan pendidik keluarga. (Pusitawati, 2010: 5)

Ritus Kusu Bue diselenggarakan setiap satu tahun sekali tepatnya dilaksanakan pada awal tahun. Pelaksanaan ritus Kusu Bue yang diperuntukan untuk perempuan ini tidak hanya melibatkan pihak perempuan saja, tetapi juga melibatkan pihak laki-laki. Terjadi pembagian kerja berdasarkan jenis kelamin. Sehingga, laki-laki serta perempuan memiliki peran khusus dalam pelaksanaan ritus Kusu Bue. (Probosiwi, 2015: 7-8)

Laki-laki dan perempuan memiliki masing-masing peran yang khusus dalam proses pelaksanaanya, namun selain itu terdapat juga peran perempuan yang bisa 
dilakukan oleh laki-laki begitu juga sebaliknya laki-laki juga bisa membantu tugas perempuan. Seperti dalam proses persiapan laki-laki boleh membantu perempuan di dapur seperti memasak bahkan membagikan makanan dan perempuan juga boleh membantu lakilaki seperti membantu menutup sao are dengan pelepah enau hingga membantu mengupas kulit kelapa (Rostiyati,2017:359-360)

Namun terdapat peran laki-laki dan perempuan dimana tidak boleh ikut campur dalam perannya masing-masing. Dalam hal ini penulis mengamati adanya peran gender yang sangat penting dan berpengaruh pada setiap prosesnya. Gender adalah perbedaan yang bukan biologis dan juga bukan kodrat Tuhan (Efendy, 2014:1-2). Oleh karena itu peran gender sangat nampak dalam ritus kusu bue tersebut. Laki-laki dan perempuan harus saling melengkapi untuk menciptakan keharmonisan dalam pelaksannaanya, sehingga ritus tersebut dapat memberikan makna dan bermanfaat bagi seluruh masyarakat (Patmisari, 2017:189-190)

Dengan itu, laki-laki dan perempuan memiliki kewajiban yang khusus dalam pelaksanaan ritus Kusu Bue, sehingga jika laki-laki atau perempuan tidak melaksanakan perannya, ritus Kusu Bue tidak akan bisa dilaksanakan. Bertolak dari hal ini peneliti melakukan penelitian tentang : Peran Gender dalam Ritus Kusu Bue.

Berdasarkan latar belakang yang telah dijelaskan di atas, adapun pemasalahan yang dapat dirumuskan penulis sebagai berikut: Bagaimana peran gender dalam pelaksanaan ritus Kusu Bue pada Masyarakat Dona Desa Naruwolo Kecamatan Jerebu'u Nusa Tenggara Timur?, Bagaimana implikasi peran gender pada pelaksanaan ritus Kusu Bue terhadap Masyarakat di Kampung Dona Desa Naruwolo
Kecamatan Jerebu'u, Nusa Tenggara Timur?

Adapun tujuan dari penelitian ini, sebagai berikut.1) Tujuan umum dari penelitian ini ialah untuk mengetahui peran gender pada pelaksanaan ritus kusu bue serta implikasi dalam pelaksanaan ritus kusu bue. 2) Mengetahui dan mengungkapkan secara khusus peran gender dalam setiap proses pelaksanaan ritus kusu bue dan implikasi peran gender dalam pelaksanaan ritus kusu bue.

\section{METODE}

Penelitian Ini menggunakan metode kualitatif yaitu jenis penelitian yang bertujuan untuk menggambarkan dan menelaah bagaimana peran gender dalam pelaksanaan ritus kusu bue baik dari persiapan hingga akhir acara di Kampung Dona. Penelitan ini menggunakan metode etnografi. Sumber data yang digunakan adalah sumber data primer dan sumber data sekunder. Sumber data primer diperoleh melalui hasil observasi dan wawancara kepada informan. Sedangkan sumber data sekunder yaitu data yang diperoleh melalui dokumen desa yang menjelaskan tentang gambaran umun di Kampung Dona seperti Laporan Pertanggungjawaban Desa tahun terbaru serta peta-peta yang menunjang data peneliti.

Teknik pengumpulan data merupakan cara yang dilakukan oleh peneliti untuk mengumpulkan data. Adapun beberapa teknik yang diakukan oleh peneliti saat melakukan penelitian yaitu,1) Teknik penentuan informan; 2) Obeservasi partisipan; 3) wawancara; 4) studi kepustakaan. Peneliti menggunaan tahapan analisis data dari Miles dan Hubermas yaitu, tahap reduksi data, tahap penyajian data, tahap penarikan kesimpulan. Analisis penelitian kualitatif menurut Miles dan Hubermas dapat disimpulkan mampu menjawab permasalahan penenlitian kualitatif. 


\section{HASIL DAN PEMBAHASAN}

\section{Pembagian Peran Gender pada Pelaksanaan Ritus Kusu Bue}

Masyarakat Dona merupakan masyarakat yang memiliki salah satu bentuk budaya daerah yaitu ritus kusu bue (gadis pingitan). Ritus kusu bue adalah suatu proses inisiasi. Inisiasi adalah upacara atau ritual yang harus djalankan orang yang akan menjadi anggta suatu perkumpulan, suatu proses peralihan masa dari masa remaja ke masa dewasa (usia perkawinan).

Dalam proses pelaksanaan ritus kusu bue tidak lepas dari peran laki-laki dan peran perempuan yang ikut serta membantu dan memiliki peran penting dalam setiap prosesnya. Peran laki-laki bisa dibantu oleh perempuan begitu juga perempuan bisa dibantu oleh laki-laki seperti dalam mempersiapkan sarana ritus. Namun ada beberapa peran yang tidak bisa digantikan seperti pada hari pertama sampai hari ke delapan. Peran gender adalah suatu set harapan yag menetapkan bagaimana perempuan atau laki-laki harus berfikir dan bertindak (Widayani, 2014: 150-151) Pada hari pertama laki-laki berperan dalam ritual ses'e. Ritual ses'e laki-laki bertugas untuk menumbuk beras serta memiliki peran dalam pengambilan keputusan jika pada saat ses'e berlangsung terdapat masalah seperti daun reba robek. Dalam peristiwa ini perempuan dilarang bertukar peran dikarenakan dalam adat masyarakat Dona jika terjadi suatu permasalahan laki-laki dari pihak ibu atau paman dari gadis kusu bue yang berhak untuk berbicara dan menentukan keputusan jika terjadi suatu permasalahan.

Hari kedua pada ritual waju pare kobho. Laki-laki disini akan mengolah beras hingga menjadi nasi diawali dari menyapih beras memasak hingga mengkonsumsi. Dalm peristiwa ini terlihat bahwa adanya pertukaran peran umum dalam ritual ini. Dalam ritual ini peran laki-laki tidak boleh digantikan oleh perempuan. Hal ini dilakukan sebagai bentuk rasa syukur kepada hasil panen serta rasa hormat kepada para perempuan (Arief, 2018: 1-2)

Hari Ke-enam, pada ritual ngapa lobho laki-laki akan ikut bersama para ngapa mencari keperluan sang gadis, namun laki-laki mmiliki tugas untuk mencari tebu putih. Tebu putih dalam masyarakat Dona melambangkan kesucian. Tebu ini akan digunakan pada hari terakhir peaksanaan kusu bue. Lakilaki ditugaskan untuk mencari tebu dikarenakan laki-laki dipercaya memiliki kekuatan untuk memotong tebu, namun laki-laki yang boleh ikut dalam ngapa lobho ini adalah saudara dari ibu sang gadis.

Pada hari ke-tujuh yang berperan dihari ini hanya lanu sao. Lan sao memiliki peran untuk memberitahu kepada semua penduduk laki-laki agar tidak keluar dari rumah dikarenakan para kusu bue akan keluar dari sao are. Pada saat ini perempuan kusu bue dianggap suci sehingga laki-laki tidak boleh dilihat oleh gadis kusu bue. Lanu sao akan memberi pengumuman yang berbunyi "masa ana haki lole moi eta one baru ana kusu bue dia menga kodho"

Yang artinya semua kaum laki-laki silahkan bergegasutuk masuk kedalam rumah masing-masing karena anak kusu bue akan keluar. Semua laki-laki harus berada didalam rumah hingga gadis kusu bue kembali masuk ke sao are dan Lanu sao akan memberikan pemberitahuan anak kusu bue sudah memasuki sao are.

Peran perempuan pada pelaksanaan ritus kusu bue yang tidak bisa dipertukarkan adalah peran dari para ngapa, gadis kusu bue, serta perempuan pengiring. Pada hari pertama para ngapa dan gadis kusu bue mengikuti ritual ses'e. Para ngapa disini bertugas unuk 
membantu para laki-laki serta memberi arahahan kepada laki-laki saat melakukan ses'e. sedangkan untuk gadis kusu bue hanya duduk dan melihat proses ritual berlangsung. Dari hari pertama hingga hari kedelapan para ngapa hanya bertugas untuk mendampingi membimbing serta mempersiapkan yang diperlukan oleh gadis kusu bue. Sedangkan untuk perempuan pengiring berperan pada hari ke-tujuh. Perempuan pendamping merupakan gadis yang akan melakukan kusu bue tahun depan. Para gadis kusu bue akan melakukan kusu bue selama tiga atau empat kali sesuai dengan kemampuan keluarga.

Ritus kusu bue terdapat peran gender di dalamnya semua memiliki peranan masing-masing dalam setiap prosesnya. Selain itu, terdapat peran yang tidak bisa dipertukarkan oleh laki-laki atau dibantu oleh laki-laki, begitu juga sebaliknya (Boediarsih, 2016: 29-30)

\section{Implikasi Peran Gender dalam Pelaksanaan Ritus Kusu Bue terhadap Masyarakat Dona}

Ritus kusu bue terdapat peran gender di dalamnya semua memiliki peranan masing-masing dalam setiap prosesnya. . Dalam hal ini peran gender juga berpengaruh pada implikasi terhadap kehidupan masyarakat Dona. Penulis mengamati terdapat empat implikasi dalam peran gender terhadap masyarakat Dona. Pertama Implikasi dalam bidang sosial. Melalui peran gender dalam pelaksanaan ritus kusu bue masyarakat Dona bisa semakin lebih harmonis, dikarenakan dalam melakukan perannya masyarakat tidak boleh memiliki permasalahan pada pihak lain yang akan ikut berperan dalam kusu bue. hal ini harus segera diselesaikan secara damai agar masyarakat dona merasa nyaman dalam melakukan perannya pada pelaksanaan ritus kusu bue (Suardi, 2016: 42-43)
Kedua peran gender memiliki implikasi pada bidang pendidikan. Peran para ngapa memberikan implikasi tentang pendidikan karakter gadis kusu bue. dalam sao are para ngapa memberikan bimbingan berupa kepedulian terhadap diri sendiri, kehormatan para gadis serta cara berperilaku dalam lingkungan masyarakat. Selain para ngapa, peran gender memberikan pendidikan berupa pelajaran tentang bagaimana menjalankan peran dalam pelaksanaan ritus kusu bue. Hal ini lebih berimplikasi kepada generasi muda dikarenakan mereka akan menjadi penerus ritus kusu bue.

Ketiga peran gender memiliki implikasi pada bidang musyawarah dan mufakat. Masyarakat akan bermusyawarah tentang keberlangsungan acara ritus kusu bue. Selain itu masyarakat akan memusyawarahkan jika di dalam keluarga terdapat suatu masalah. Dalam musyawarah ini dipimpin oleh laki-laki. Biasanya lakilaki tersebut adalah ketua suku dari suku tipo. Ketika musyawarah laki-laki mengambil peran dalam pengambilan keputusan dan melibatkan keluarga lainnya untuk menentukan jalan keluar. (Lestari, 2015:6-7). Setelah melakukan musyawarah semua permaslahan akan mencapai suatu kesepakatan diaman pihak yang bermaslah atau memiliki konflik akan berdamai kembali demi kelancaran pelaksanaan ritus kusu bue.

$\mathrm{Ke}$ empat peran gender memiliki implikasi pada bidang religi. Masyarakat Dona memiliki ngadhu dan bhaga. Ngadhu bhaga merupakan simbol dari leluhur laki-laki dan perempuan . Peran gender dalam ritus kusu bue merupakan keseimbangan dalam pelaksanaan ritus. Adanya peran gender dalam peaksanaan ritus berimplikasi terhadap masyarakat Dona yaitu menimbulkan keharmonisan di dalam pelaksanaan ritus kusu bue. 
Seain itu adanya peran laki-laki dan perempuan merupakan keseimbangan dalam pelaksnaan ritus kusu bue.

Ritus kusu bue merupakan ritus yang lebih dulu ada di masyarakat Dona dibandingkan Agama Khatolik. Agama Khatolik merupakan agama yang banyak dianut oleh masyarakat Dona. Dalam Khatolik dijelaskan tentang kemuliaan Bunda Maria. Masyarakat sangat menghormati Bunda Maria dimana sebagai simbol kemuliaan perempuan. Oleh sebab itu masyarakat Dona sangat menghargai perempuan serta menjaga kehormatan perempuan dalam masyarakat Dona khususnya.

Peran gender sangat berpengaruh dalam keberlangsungan upacara ritus. Masyarakat Dona membagi peran untuk laki-laki maupun perempuan, mereka bekerja sama saling tolong menolong dalam melaksanakan ritus kusu bue. Hal ini dilakukan demi tercapainya tujuan dalam ritus kusu bue. Selain itu Implikasi dari peran gender juga berpengaruh terhadap kehidupan masyarakat Dona. Yang menggandung implikasi positif sehingga sangat bermanfaat untuk masyarakat Dona.

\section{SIMPULAN}

Berdasarkan analisis penelitian mengenai Peran Gender dalam Ritus Kusu Bue di Kampung Dona, Desa Naruwolo, Kabupaten Ngada, Nusa Tenggara Timur, maka dapat disimpulkan sebagai berikut : Ritus kusu bue merupakan bagian dari upacara Reba. Ritus kusu bue dilaksanakan selama delapan hari mulai dari tanggal 1 Januari hingga 8 Januari. Kusu Bue diambil dari dua kata yaitu kusu dan bue. Kusu berarti pingit dan bue berarti gadis. Jadi ritus kusu bue adalah ritus yang dperuntukan untuk perempuan, yang dimana perempuan tersebut akan dipingit selama 8 hari 7 malam. Perempuan yang bisa mengikuti acara ini adalah perempuan yang sudah mengalami menstruasi. Dalam pelaksanaan ritus kusu bue ini terdapat keterlibatan pran gender. Lakilaki dan perempuan memiliki keterlibatan dalam proes pelaksanaannya, mulai dari persiapan hingga acara berakhir. Peran peempuan yang mendominasi dalam ritus kusu bue ini adalah peran para ngapa yaitu mereka selalu membimbing gadis kusu bue selama masa pingitan, dikarenakan pada masa pingitan tersebut siapapun tidak boleh bertemu dengan gadis kusu bue termasuk ayahnya sendiri. Peran laki-laki yang mendominasi adalah paman dari gadis kusu bue. Paman gadis kusu bue harus berasal dari keuarga ibu. Dalam setiap prosesnya paman lah yang akan mempertanggung jawabkan jika terjadi suatu permasalahan termasuk pengambilan keputusan. Peran laki-laki dan perempuan memang sangat penting pada setiap prosesnya. Oleh karena itu terdapat implikasi dalam peran gender terhadap masyarakat Dona. Implikasi peran gender terhadap masyarakat Dona adalah Implikasi pada bidang social dimana dapat mempererat hubungan persaudaraan serta menumbuhkan rasa persatuan dan kesatuan antar keluarga dan masyarakat. Kedua Implikasi peran gender pada bidang pendidikan. Peran gender juga memiliki implikasi dalam bidang pendidikan yaitu dapat menumuhkan kesadaran terhadap warisan budaya nenek moyang dan dapat menghormati serta menghargaidiri sendiri. Ketiga Implikasi peran gender dalam bidang musyawarah mufakat yaitu dapat memecahkan suatu permasalahan dalam msyarakat dan dapat mengurangi perselisihan. Kemudian impikasi yang terakhir adalah dalam bidang religi. Seperti timbulnya rasa menghrmati dan menghargai sesama, munculnya perasaan tentram dan nyaman dalam keluarga maupun masyarakat, serta lebih meningkatkan rasa menghormati terhadap perempuan. Manusia percaya 
bahwa "Yang Suci " itu ada diluar kemampuan dan kekuasaan, sehingga manusia meminta perlindungannya (Agus, 2018:7-8)

Bagi masyarakat pewaris budaya khususnya masyarakat Dona. Penilaian atas baik dan buruknya sikap dan kepribadian seseorang terutama pada anak gadis, pertama-tama ditentuakan dari dan oleh pendidikan dan pembinaan dari dalam keluarga yang diberikan oleh orang tua. Keluarga telah menanamkan sikap yang baik mulai anak kecil menginjak remaja sampai membentuk keluarga baru. Hal ini bertujuan memberikan nilai-nilai hidup yang berguna bagi perkembangan dan masa depan anak dalam kehidupan masyarakat nilai-nilai hidup yang baik, yang diajarkan dalam budaya adat istiadat setempat hendaknya tetap diselenggarakan dan dipertahankan selamanya.

Kepada lembaga pendidikan Hendaknya mendidik, mendorong, dan membina mahasiswa untuk selalu mencintai dan menghayati nilai-niai luhur budaya demi menghasilkan tamatan yang berwawasan budaya. Hendaknya memperkenalkan kepada mahasiswa untuk melakukan penelitian-penenlitian tentang kebudayaan di pelosok tanah air umumnya untuk wilayah Flores. Untuk mahasiswa diharapkan untuk melakukan penelitian lebih lanjut dan lebih mendalam tentang warisan budaya salah satunya kusu bue.

\section{REFERENSI}

Agus, Arnoldus Yansen. 2018 "Ritual Penti Pada Masyarakat Desa Ndehes, Kecamatan Wae Ri'I, Kabupaten Manggarai, Flores, Nusa Tenggara Timur". Denpasar: Jurnal Humanis Vol. 22 No. 1: 7-8
Arief, Mufardisah. 2018. “ Hubungan Gaya Belajar Berdasarkan Gender Dengan Hasil Belajar Pada Mahasiswa Teknologi Pendidikan Universitas Negeri Malang" Malang: Jurnal Kajian Teknologi Pendidikan. Vol 1 No. 1: 1-2

Asmarani, Ratna. 2017. "Perempuan Dalam Perspektif Kebudayaan" Semarang: Jurnal Sabda. Vol 12 No $1: 3-4$

Boediarsih. 2016 “ Persepsi Remaja tentang Peran Gender dan Gender Seksualitas di Kota Semarang". Semarang: Jurnal Promosi Kesehatan Indonesia Vol. 11 No 1: 29-30

Dhogo, Cristologus. 2009. SU'I UWI "Riitus Budaya Ngada dalam Perbandingan dengan Perayaan Ekaristi". Maumere : Ledalero

Efendy, Rustan. 2014 " Kesetaraan Gender Dalam Pendidikan" Parepare: Jurnal Al-Maiyyah Vol. 7 No. 2: 1-2

Lestari, Dyah Purbasari Kusumaning Putri. 2015. " Pembagian Peran Dalam Rumah Tangga Pada Pasangan Suami Istri Jawa" Surakarta: Jurnal Penelitian Humaniora Vol. 16 No.1: 6-7

Patmisari, Ida Ayu. 2017 "Pendidikan Nilai Agama Hindu dalam Upacara Menek Bajang di Desa Yehembang Kecamatan Mendoyo Kabupaten Jembrana" Denpasar: Jurnal Penelitian Agama Hindu. Vol 1 No. 2 : 189-190.

Paul Ardt, SVD. 2009. Masyrakat Ngada, Flores : Nusa Indah 
Probosiwi, Ratih. 2015 “ Perempuan Dan Perannya Dalam Pembangunan Kesejahteraan Sosial" Yogyakarta: Jurnal Kajian Ilmu Admnistrasi Negara Vol. 3 No. 1: 7-8

Puspitawati, Herien. 2010. "Persepsi Peran Gender Terhadap Pekerjaan Domestik Dan Publik Pada Mahasiswa IPB" Purwokerto: Jurnal Studi Volume 5 No. 1: 5-6

Rostiyati, Ani. 2017 “ Peran Perempuan Pada Upacara Tradisional Rahengan di Desa Citatah, Kabupaten Bandung Barat" Bandung: Jurnal Peneliti Utama Balai Pelestarian dan Nilai Budaya Jawa Barat. Vol 9 No 3: 359-360.

Suardi. 2016 “ Implikasi Sosial Diskriminasi Gender" Makasar: Jurnal Sosiologi Pendidikan Humanis. Vol 1 No. 1

Widayani, Ni Made Diska. 2014 "Kesetaraan Dan Keadilan Gender Dalam Pandangan Perempuan Bali: Studi Fenomenologis Terhadap Penulis Perempuan Bali” Semarang: Jurnal Psikologi Undip Vol. 13 No 2: 150-151

Yohanes Vianey, Watu. 2010. Pata Dela. Kupang : Gita Kasih 